\title{
Performance Evaluation of an Integrated Starter-Alternator with an IPM Synchronous Machine under Sensor-less Operation
}

\author{
Zhuang $\mathrm{Xu}^{\dagger}$, M. F. Rahman*, G. Wang**, and Dianguo $\mathrm{Xu}^{* *}$ \\ $\dagger^{* *}$ School of Electrical Eng. and Automation, Harbin Institute of Technology, Harbin, China \\ ${ }^{*}$ School of Electrical Engineering and telecommunications, The University of New South Wales, Sydney, Australia
}

\begin{abstract}
This paper presents performance evaluation of an Integrated Starter-Alternator (ISA) prototype with an Interior Permanent Magnet (IPM) synchronous machine under sensor-less operation. To attain a high starting torque at zero speed and in subsequent extremely low speed range, a hybrid signal injection method is proposed. At higher speed, an improved stator flux observer is used for the stator flux estimation. This observer is able to produce accurately-estimated stator flux linkage for high performance Direct Torque and Flux Control (DTFC) implementation. The sensor-less DTFC IPM synchronous machine drive takes full advantage of the capacity of the power converter and fulfills the control specifications for the ISA. The trajectory control algorithm responds rapidly and in a well behaved manner over a wide range of operating conditions. The experimental results verify the feasibility and advantages of the system.
\end{abstract}

Key Words: Interior permanent magnet synchronous machine, ISA, Sensor-less operation

\section{INTRODUCTION}

The average electrical power load of automobiles is increasing to $10 \mathrm{~kW}$ [1]. In hybrid or electrical vehicles where propulsion is achieved with high power electric motors, power demand will be farther more. In order to cope with the increasing load, the automotive power system has been proposed to increase the dc bus voltage from $14 \mathrm{~V}$ to $42 \mathrm{~V}$. The increment of this power demand also leads to an electrical machine with a torque that is in the range of the starting torque demands of an Internal Combustion Engine (ICE) of big vehicles. A solution to making this new system economically viable is to develop an integrated starter alternator (ISA) system. It is not only economical but also a space saver, specially, when the machine is directly coupled to the engine. A single electrical machine as a starter-alternator can be operated for both ICE starting and successive power generation features. The requirements of a direct-drive ISA include a high starting torque in the low speed range as well as a smooth transition from motor to generator operation mode at higher speeds. A number of electrical machines have been considered for this application. The Interior Permanent Magnet machine with

Manuscript received Aug. 30, 2011; revised Dec. 4, 2011

Recommended for publication by Associate Editor Jung-Ik Ha.

$\dagger$ Corresponding Author: zhuang.xu@gmail.com

Tel: +86-451-86418442, Harbin Institute of Technology

* School of Electrical Engineering and telecommunications, the University of New South Wales, Australia

** School of Electrical Eng., and Automation, Harbin Institue of Technology, China wide Constant Power Speed Range (CPSR) is an ideal choice [2]. The multilayer IPM machine and axially laminated IPM machines are capable of wide flux-weakening range. However, the significant $q$-axis saturation seen in these machines can cause problem during high load and speed condition [3]. The segmented IPM machine [4], [5] can provide a very wide CPSR; it can be used for applications such as ISA.

In favor of segmented IPM machines as ISA, it had been tested that it can offer a wide CPSR with a simpler rotor configuration. The starter/alternator operates in torque control mode and the speed loop is not used. However, a speed or position sensor is undesirable in a high speed drive system due to the following reasons:

(1) Cost and reliability;

(2) Accuracy limited because of environmental factors;

(3) Maintenance requirements;

(4) Shaft extension and mounting arrangements.

In the existing literature, the proposed algorithms for sensorless speed control of IPM motors can be summarized as follows:

(1) Open loop back-emf based estimators [6].

(2) Estimation based on high-frequency signal injection [7]

(3) Closed-loop observers based on advanced models [8][13].

At very low speeds, the performance of the methods in the first category is poor. One of the reasons is high sensitivity of the estimators to un-modeled nonlinearities, disturbance, and model parameters detuning. Signal injection techniques 
take advantages of the magnetic saliency of the machine to detect the rotor position through the injection of proper test signals [7]. This method offers a solution both for standstill and low speed operation, but they require high precision in the measurement, increase the complexity of the hardware and generate undesirable noises. Since accurate and robust estimation of motor variables which are not measured is crucial for high performance sensor-less drives.

In order to fulfill the control requirements for the ISA drive system in wide operation range, a DTFC scheme integrated with sensor-less technologies adhered to different speed ranges is discussed and implemented in the paper for the ISA with an IPM synchronous machine. One of the attractive features of DTFC is that the requirement for the continuous rotor angle is eliminated. The DTFC operates in the stationary reference frame rather than any rotating reference frame. Any attempt to superimpose high frequency signals onto the rotating $d-q$ axis violates the principles of the original DTFC. To retain the merits of the DTFC, at zero-low speeds, a high-frequency rotating carrier is injected into stator winding to abstract the magnet pole position. A phase-lock-loop is designed to adjust the constructed-error signal containing information about rotor position.

Speed estimation using a simplified Kalman filter is integrated with an improved stator flux observer. for the sensorless direct torque and flux control of the IPM synchronous machine. The development of the observer is based on the virtual rotor flux estimation. The observer has better dynamic behavior, disturbance resistance and high accuracy estimation ability. The maximum torque per ampere (MTPA) and field weakening $(\mathrm{FW})$ operations are also incorporated into the system.

\section{Integrated StARTER AND Alternator With AN IPM MACHINE}

In this work, the prototype IPM machine [5] is further optimized using finite element method exclusively. The magneto-static FEM was used to calculate the air-gap flux, and variation of dq-axis flux linkages with currents. On the other hand, the back EMF, cogging torque, iron losses and electromagnetic torque are estimated using time-stepping and external circuit-coupled finite element method. Throughout the optimization process, the rotor and the stator geometry, stator slots, permanent magnet segments and iron bridges have been further designed and optimized. The best possible solution was determined depending on the resultant CPSR.

The stator dimension given in [5] was used in this work in order to compare the performance of the segmented IPM machine [5] with the optimized IPM machine designed for ISA application. As illustrated in Fig. 1, the rotor geometry of the re-designed, segmented IPM machine is optimized by the flow chart given in [5]. The width of the iron-bridges is further optimized. The optimum length of the magnet in the direction of magnetization is found to be $8 \mathrm{~mm}$ and a bonded $\mathrm{NdFeB}$ with remanance $0.71[\mathrm{~T}]$ is selected as the suitable magnet material. The standard electrical steel grade (Lycore 140 ) is selected for the stator and rotor core.
A low power laboratory ISA prototype, which could comply with ISA requirements only for small vehicles, has been designed and tested. A segmented IPM machine is optimized for this particular application. Further, the design optimization was processed and the best possible rotor magnet and geometry design illustrated in Fig. 1 has been achieved. No-load fluxdensity distribution of the prototype optimized Segmented IPM machine is shown in Fig. 2.

The cogging torque in the Permanent Magnet machines is a concern for low speed applications. The cogging torque of the machine was calculated in the finite element by the method discussed in [2]. The Fig. 3 shows the estimated cogging torque of the IPM machine compared to the Segmented IPM machine. The peak cogging torque of the optimized IPM machine is almost 7 times less than that of the Segmented IPM machine. It is noted that in both machines, the configuration of the stator is the same.

During starting, the ISA machine work as a motor which is fed from the DC bus of the system. The torque developed in the optimized segmented IPM motor with stator excitation is limited by the DC bus. The rated continuous torquespeed envelope and power capability of the segmented IPM machine for generation is also estimated. The constant torque is available up to around $1200 \mathrm{r} / \mathrm{min}$ and above this speed constant power operation starts that needs the flux-weakening control.

With the optimization for the segmented IPM machine, improved performance has been achieved:

(1) Cogging torque has been greatly reduced (Fig.3).

(2) During Starting, a high torque output is required; the flux density of teeth and air gap is reasonably distributed.

(3) A high torque output at start is obtained at very low speed by increasing the magnetizing current to raise EMF effectively as shown in Fig. 4.

(4) By weakening magnetic flux to reduce EMF, such that in high-speed generation mode, the DC bus voltage goes down to the range required by the ISA specification.

\section{SENSORLESS CONTROL OF THE ISA}

\section{A. High Frequency Carrier Injection at zero-low Speeds}

To retain the merits of the DTFC, high frequency signals are superimposed onto the reference voltage in the stationary $\alpha-\beta$ reference frame. The relevant voltage equation for IPM synchronous motors is

$$
\vec{u}_{s}=R_{s} \vec{i}_{s}+\frac{d \vec{\lambda}_{s}}{d t} .
$$

$\vec{u}_{s}, \vec{i}_{s}$ and $\vec{\lambda}_{s}$ are stator voltage, current and flux vector respectively. When a high-frequency rotating voltage carrier is injected into the stator winding as illustrated in Fig.5, assuming that the rotor speed is much smaller than the carrier frequency $\omega_{c}$ and the stator resistance is negligible compared to the high frequency stator reactance. Equation (1) can be simplified as:

$$
\vec{u}_{s} \cong \frac{d \vec{\lambda}_{s}}{d t} .
$$




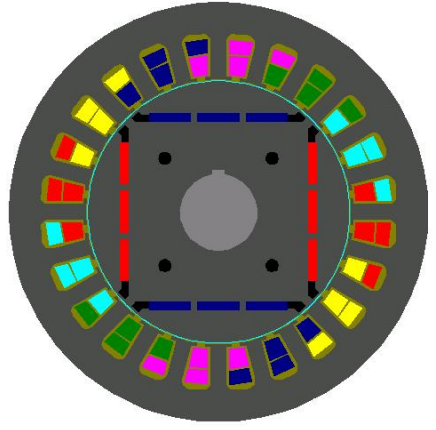

(a)

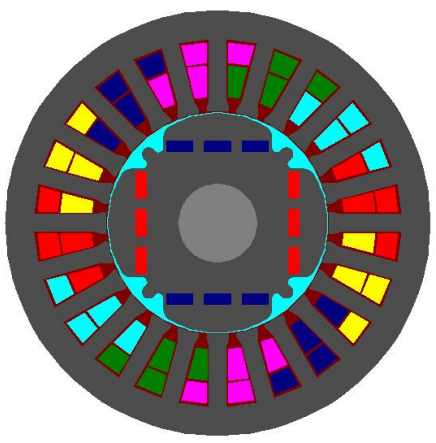

(b)

Fig. 1. (a) Segmented magnet IPM machine FEM (IPM1). (b) Optimized IPM machine (IPM2).

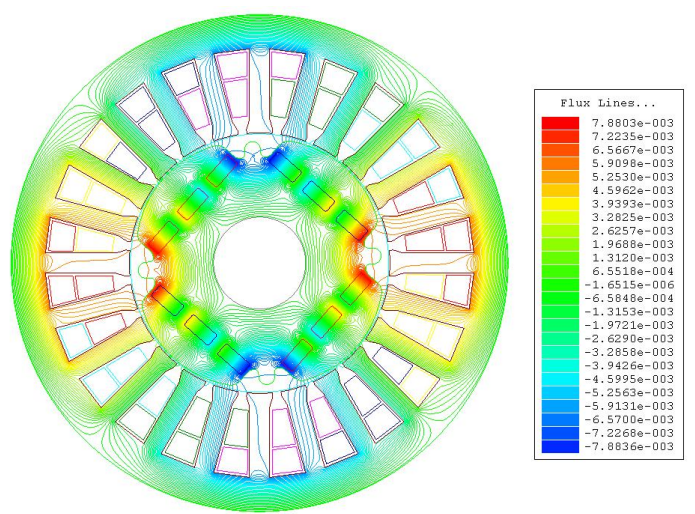

Fig. 2. No-load flux-density distribution of the prototype optimized Segmented IPM machine.

The inductance matrix is expressed as

$$
L_{s \alpha \beta}=\left[\begin{array}{cc}
\Sigma L_{s}-\Delta L_{s} \cos 2 \theta_{r e} & -\Delta L_{s} \sin 2 \theta_{r e} \\
-\Delta L_{s} \sin 2 \theta_{r e} & \Sigma L_{s}+\Delta L_{s} \cos 2 \theta_{r e}
\end{array}\right]
$$

where $\Sigma L_{s}=\frac{L_{q}+L_{d}}{2}, \Delta L_{s}=\frac{L_{q}-L_{d}}{2}$ and $\theta_{r e}$ is the electrical position of the rotor.

The $\alpha-\beta$ components of the stator flux vector can be denoted as:

$$
\left[\begin{array}{l}
\lambda_{\alpha} \\
\lambda_{\beta}
\end{array}\right]=L_{s \alpha \beta}\left[\begin{array}{c}
i_{\alpha} \\
i_{\beta}
\end{array}\right]+\left[\begin{array}{c}
\lambda_{f} \cos \theta_{r e} \\
\lambda_{f} \sin \theta_{r e}
\end{array}\right]
$$

$\lambda_{\alpha}, \lambda_{\beta}, i_{\alpha}$ and $i_{\beta}$ are the stator flux and stator current components in the stationary $\alpha-\beta$ reference frame. The rotor position can be sensed by exploiting the saliency of the rotor.

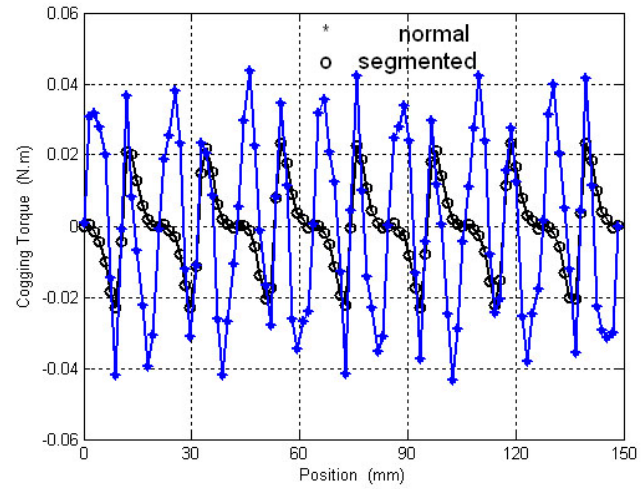

(a)

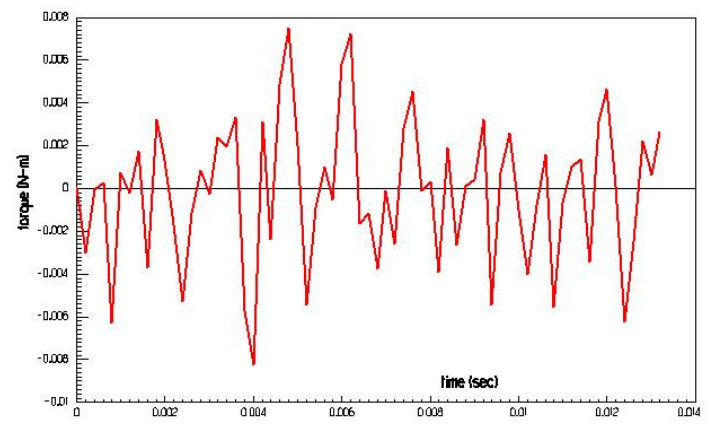

(b)

Fig. 3. Cogging torques of the segmented magnet IPM machine and optimized IPM machine, Cogging torque is reduced by around $1 / 7$.

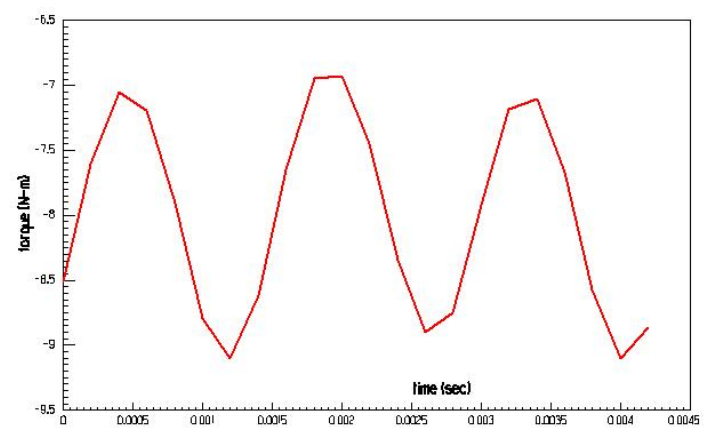

Fig. 4. output torque by increasing the magnet flux when $i_{d}=10 \mathrm{~A}$

From (2) and (4), high frequency currents can be derived as:

$$
\left[\begin{array}{c}
i_{\alpha H} \\
i_{\beta H}
\end{array}\right]=\left[\begin{array}{c}
I_{p} \sin \omega_{c} t+I_{n} \sin \left(2 \theta_{r e}-\omega_{c} t\right) \\
-I_{p} \cos \omega_{c} t-I_{n} \cos \left(2 \theta_{r e}-\omega_{c} t\right)
\end{array}\right]
$$

Where $I_{p}$ and $I_{n}$ are the amplitudes of the high frequency positive and negative components. $I_{p}=\frac{U_{s} \Sigma L_{s}}{\omega_{c}\left(\Sigma L_{s}^{2}-\Delta L_{s}^{2}\right)}$ and $I_{n}=\frac{U_{s} \Delta L_{s}}{\omega_{c}\left(\Sigma L_{s}^{2}-\Delta L_{s}^{2}\right)}$

It can be found that the negative component of the high frequency current contains information about the rotor position. A demodulation is designed to filter out positive components by using band-pass filtering and extract high frequency negative current component. An error signal can be constructed by demodulating high frequency negative component $i_{\alpha n}$ and $i_{\beta n}$ as shown in (6). The estimated angle can be obtained by using a Phase-Lock-Loop (PLL). The demodulation algorithm 


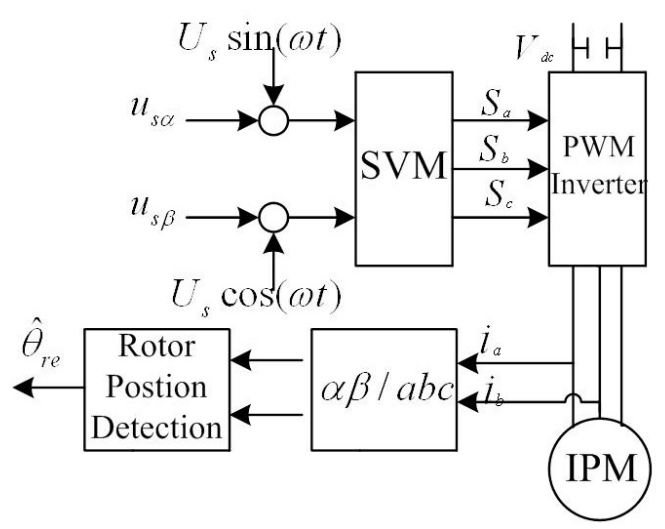

Fig. 5. High Frequency Carrier Injection.

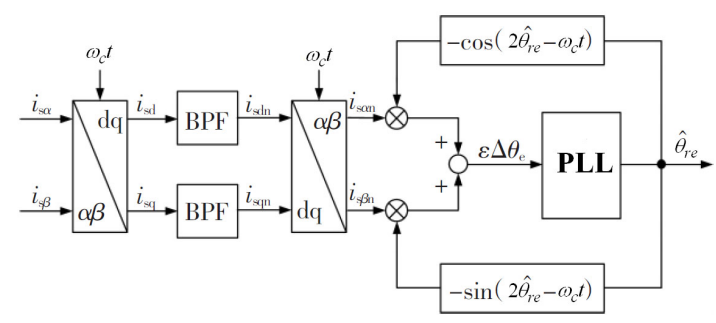

Fig. 6. The demodulation algorithm for the rotor position detection.

is shown in Fig. 6.

$$
\begin{aligned}
\varepsilon \Delta \theta_{e} & =-i_{\alpha n} \cos \left(2 \theta_{r e}-\omega_{c} t\right)-i_{\beta n} \sin \left(2 \theta_{r e}-\omega_{c} t\right) \\
& =I_{n} \sin 2\left(\hat{\theta}_{r e}-\theta_{r e}\right) \approx I_{n} 2 \Delta \theta_{r e} .
\end{aligned}
$$

Once the rotor angle is known, the stator flux vector can be estimated by (4).

In order to test the effectiveness of the high frequency carrier injection method, the algorithm was implemented on DSP TMS320F2808. For comparison of the estimation accuracy, an absolute encoder (ECN 1113) from Heidenhain had been installed on the rotor shaft to measure the actual rotor position. The PWM switching frequency is set to be 10kHz. Fig. 7 shows the experimental results for initial rotor position estimation. The real rotor angle was 45 electrical degrees. Fig. 7 (a)-(b) shows the extracted high frequency negative component $i_{\alpha n}$ and $i_{\beta n}$. The error signal $\varepsilon \Delta \theta$ and estimated position are displayed in (c)-(d). It can be seen that the convergence value is 50.3 degrees which is quite close to the measure one. The ellipse of high frequency stator currents in stationary reference frame is illustrated in Fig.8. The major axis indicates the direction of the rotor position. A method to identify the polarity of the magnet is described in [7], which utilizes the magnetic saliency effect.

\section{B. An improved stator flux observer}

The electromagnetic torque of an IPM machine is governed by

$$
T_{e m}=\frac{3}{2} P\left[\lambda_{f} i_{q}+\left(L_{d}-L_{q}\right) i_{d} i_{q}\right]
$$

where $T_{e m}$ is the estimated torque, $P$ is number of pole pairs, $\lambda_{f}$ is EMF constant, $i_{d}$ and $i_{q}$ are currents in rotor reference frame.

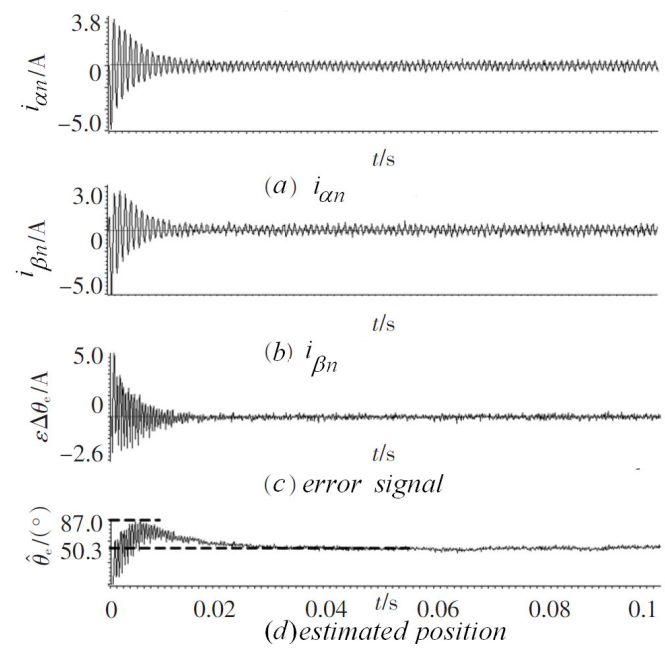

Fig. 7. Initial rotor position estimation by using high-frequency voltage injection $\theta_{r e}=45^{\circ}$. (Experimental results).

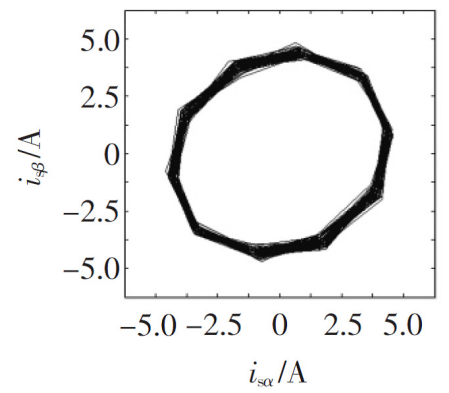

Fig. 8. High frequency currents in stationary reference frame.

A virtual flux can be defined as $\lambda_{v}=\lambda_{f}+\left(L_{d}-L_{q}\right) i_{d}$, which has two terms - the permanent magnet flux linkage and a salient flux linkage. The torque equation becomes $T_{e m}=\frac{3}{2} P \lambda_{v} i_{q}$. The magnetic anisotropy in the model of IPM machines is covered and expressed as:

$$
\left\{\begin{array}{l}
u_{d}=R_{s} i_{d}+L_{q} \frac{d i_{d}}{d t}-\omega_{r e} L_{q} i_{q}+\frac{d \lambda_{v}}{d t} \\
u_{q}=R_{s} i_{q}+L_{q} \frac{d i_{q}}{d t}+\omega_{r e} L_{q} i_{d}+\omega \lambda_{v}
\end{array}\right.
$$

where $u_{d}$ and $u_{q}$ are voltages in rotor frame and $\omega_{r e}$ is rotor electrical speed.

The current model equations in Fig.9 in a stationary reference frame are obtained by converting the motor stator flux equations in $d-q$ frame into the $\alpha-\beta$ reference frame.

$\left[\begin{array}{l}\lambda_{\alpha} \\ \lambda_{\beta}\end{array}\right]=\left[\begin{array}{cc}\cos \theta_{r e} & -\sin \theta_{r e} \\ \sin \theta_{r e} & \cos \theta_{r e}\end{array}\right]\left[\begin{array}{l}\lambda_{d} \\ \lambda_{q}\end{array}\right]=\left[\begin{array}{c}L_{q} i_{\alpha}+\lambda_{v} \cos \theta_{r e} \\ L_{q} i_{\beta}+\lambda_{v} \sin \theta_{r e}\end{array}\right]$.

The virtual rotor flux is aligned along the d-axis as the permanent flux linkage does and $\theta_{r e}$ can be retrieved by using

$$
\theta_{r e}=\tan ^{-1}\left(\frac{\lambda_{v \alpha}}{\lambda_{v \beta}}\right)=\tan ^{-1}\left(\frac{\lambda_{\beta}-L_{q} i_{\beta}}{\lambda_{\alpha}-L_{q} i_{\alpha}}\right) .
$$

In the stator reference frame, the stator flux is given by

$$
\frac{d \hat{\lambda}_{s}}{d t}=u_{s}-R_{s} i_{s}
$$

A correction voltage term $\vec{u}_{c}=k_{p}\left(1+\frac{k_{i}}{s}\right)\left(i_{s}-\hat{i}_{s}\right)$ is added to the integration operation. The correction term is obtained 


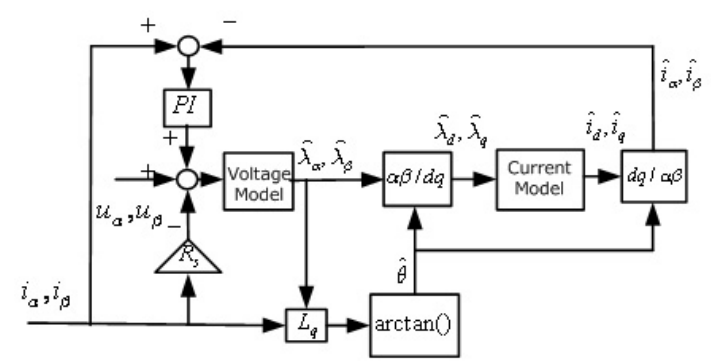

Fig. 9. The stator flux observer with voltage-current models.

by comparing the measured stator current with the estimated current from the machine model. The voltage model equations are derived as:

$$
\frac{d}{d t} \hat{\lambda}_{s}=-R_{s} i_{s}+u_{s}+u_{c}
$$

\section{Speed estimation using a simplified Kalman filter}

A simplified Kalman filter was constructed to minimise the time delay of the estimated speed behind the real rotor speed and improve the transient behavior of the speed estimation. This method [14] was originally used for speed estimation from sin/cosine revolver signals. In this thesis, the Kalman filter is adopted to retrieve speed and position information from the observed salient EMFs in (13).

A state model for the rotor position $\theta(k)$ and speed $\omega_{r e}(k)$

$$
\left\{\begin{array}{l}
\theta_{r e}(k+1)=\theta_{r e}(k)+T \cdot \omega_{r e}(k) \\
\omega_{r e}(k+1)=\omega_{r e}(k)+w^{\prime}(k) \\
w^{\prime}(k+1)=w^{\prime}(k)+w(k)
\end{array}\right.
$$

where $\mathrm{T}$ is the sampling period and $w(k)$ is white noise of zero mean. The speed is predicted as ramp changes hence should be modelled as a double integration of the noise $w(k)$ to avoid a lagging estimate during transients.

The output signals from (13), $\hat{\lambda}_{v \alpha}$ and $\hat{\lambda}_{v \beta}$ are sine and cosine of the rotor position and can be nominalised as

$$
\left[\begin{array}{l}
y_{1} \\
y_{2}
\end{array}\right]=\left[\begin{array}{c}
\cos \theta_{r e}(k) \\
\sin \theta_{r e}(k)
\end{array}\right]+\left[\begin{array}{c}
v_{1}(k) \\
v_{2}(k)
\end{array}\right]
$$

A state space model is built with state vector $x=$ $\left[\begin{array}{ccc}\theta_{r e} & \omega_{r e} & w^{\prime}\end{array}\right]^{T}$.

$$
\left\{\begin{array}{l}
x(k+1)=F x(k)+w(k) \\
y(k)=h(x(k))+v(k)
\end{array}\right.
$$

where $F=\left[\begin{array}{lll}1 & T & 0 \\ 0 & 1 & 1 \\ 0 & 0 & 1\end{array}\right], h(x)=\left[\begin{array}{c}\cos \left(\theta_{r e}\right) \\ \sin \left(\theta_{r e}\right)\end{array}\right]$

The Kalman filter gain is

$$
K=\left[\begin{array}{ll}
0 & k_{1} \\
0 & k_{2} \\
0 & k_{3}
\end{array}\right] \cdot\left[\begin{array}{cc}
\cos \widehat{\theta}_{r e} & \sin \widehat{\theta}_{r e} \\
-\sin \widehat{\theta}_{r e} & \cos \widehat{\theta}_{r e}
\end{array}\right]
$$

The gains can be pre-calculated in the filter design procedures using Matlab's dlqe command.

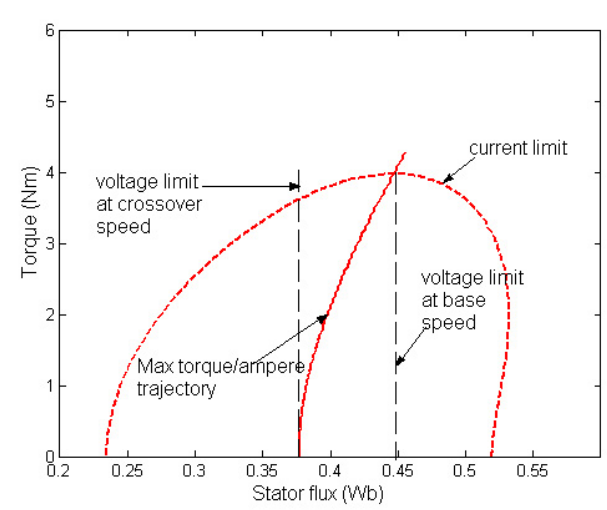

Fig. 10. The MTPA orbit calculated by using fixed nominal parameters.

The final equations for the rotor position and speed are written explicitly as

$$
\left\{\begin{array}{l}
\varepsilon(k)=y_{2}(k) \cos \widehat{\theta}_{r e}(k)-y_{1} \sin \widehat{\theta}_{r e}(k) \\
\widehat{\theta}_{r e}(k+1)=\widehat{\theta}_{r e}(k)+T \hat{\omega}_{r e}(k)+k_{1} \varepsilon(k) \\
\widehat{\omega}_{r e}(k+1)=\widehat{\omega}_{r e}(k)+w^{\prime}(k)+k_{2} \varepsilon(k) \\
w^{\prime}(k+1)=w^{\prime}(k)+k_{3} \varepsilon(k) .
\end{array}\right.
$$

\section{MTPA TRAJECTORY IN TORQUE-FLUX PlANE CONSIDERING SATURATION}

For IPM synchronous machines, additional reluctance torque can be produced by the saliency. In order to improve torque production in the constant torque region, maximum torque-per-ampere (MTPA) control is adopted.

To extend the speed range of the IPM motor drive, the field weakening $(\mathrm{FW})$ trajectory is incorporated with the DTFC. The trajectories (MTPA and FW) in $d-q$ plane in terms of currents are mapped onto the $T-\lambda_{s}$ plane [16]. The coordinates of id and iq along the MTPA trajectory in $d-q$ plane can be mapped onto the $T-\lambda_{s}$ plane. Based on the trajectories in the $T-\lambda_{s}$ plane, the stator flux linkage command is determined by the torque, which is the output of the speed controller, for constant torque or field weakening operations.

Fig. 10 shows the MTPA orbit calculated by using fixed nominal parameters. The trajectory is a function of $L_{d}, L_{q}$ and $\lambda_{f} . L_{d}$ and $L_{q}$ vary non-linearly with the increase of operating currents. Therefore, the calculation of the real MTPA should consider parameter variation $\left(L_{d}\right.$ and $\left.L_{q}\right)$ including iron saturation. Fig. 11 shows the MTPA trajectory including iron saturation with experimentally measured parameters. $\lambda_{f}$ is assumed to be constant.

The torque production is improved with the consideration of parameter variation including saturation in computation of MTPA. Fig. 12 shows the comparison of MTPA with and without saturation included, it is seen that with the increase of operating current, there is an increasing torque production when iron saturation is considered.

\section{EXPERIMENTAL RESULTS}

A DTFC IPM synchronous motor drive developed by us in [15] was implemented in real-time on TMS320F2812 DSP board and EPM570CPLD from Altera. The DSP controller 


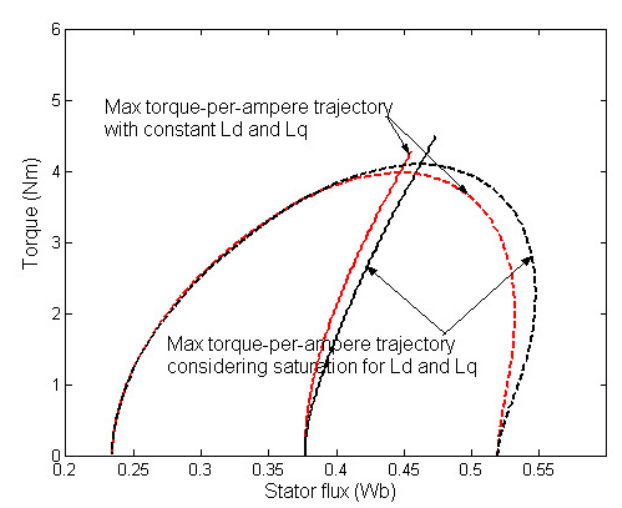

Fig. 11. the MTPA trajectory including iron saturation with experimentally measured parameters.

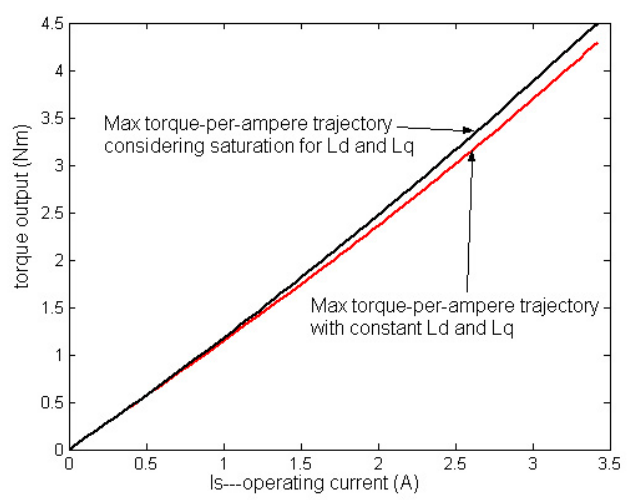

Fig. 12. The comparison of torque production using MTPA with and without saturation included.

board handles the torque and stator flux control strategy and the stator flux estimation algorithms. The CPLD deals with the logics of PWM driving signals and protects the IGBT power module. The sampling time of the inner control loops was kept at $100 \mu$ s and that of the outer speed control loop was set as $500 \mu \mathrm{s}$. The rotor speed is obtained from high frequency carrier injection method at zero and very low speed and from the stator flux observer at higher speed. An absolute encoder (ECN 1113) is only installed for checking the accuracy of the sensor-less techniques. The photos for the description of the experimental implementation are illustrated in Fig. 13 and 14. Fig. 15 demonstrates the overall control scheme for the variable structure DTFC IPM drive [15]. The parameters of the motor under test are listed in Table I and II in Appendix. Initially, IPM1 was tested and then wider speed was achieved with IPM2.

Firstly, the steady state performance of the ISA drive system was checked when the motor ran at 5rpm with full load. Fig. 16 depicts the tested waveforms at $5 \mathrm{rpm}$. The drive system was stable and the speed and position estimation errors were kept small by the accuracy of the signal injection method.

Then, sensor-less zero speed operation with sudden adding and removal of nominal torque steps is depicted in Fig. 17. The load was initially applied to the machine and was subsequently removed. It can be observed that the estimated speed tracks the actual speed very well and the zero-speed regulation was very tight during transients and in the steady-state.

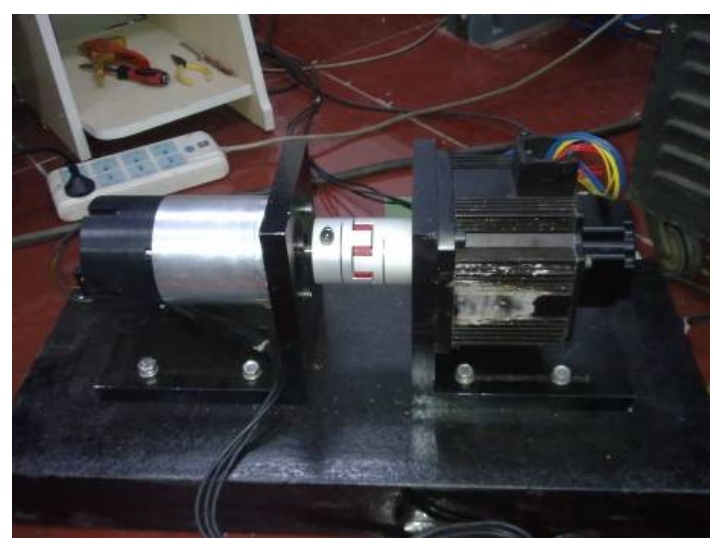

Fig. 13. the IPM synchronous machine under testing.

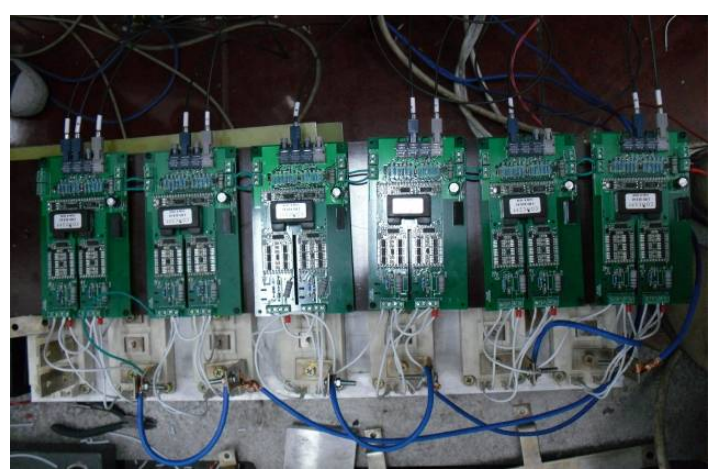

Fig. 14. The inverter for experimental test bench.

Fig. 18 is a plot of speed sensor-less reversal between +1000 and $-1000 \mathrm{rpm}$. The estimated speed closely follows the measured speed with very little time delay. Around zero speed, there is a $35 \mathrm{rpm}$ speed estimation error for a very short period of 0.05 seconds. This is because the back EMFs are too small around zero speed. The stator flux estimation is plotted in the bottom subplot of Fig. 18.

The dynamic performance of the drive system under flux weakening operation is shown in Fig.19 and 20. The machine was accelerated from $500 \mathrm{rpm}$ to $3500 \mathrm{rpm}$. When the rotor speed is lower than the base speed (1500 rpm), the MTPA trajectory is selected. Conversely, the current and voltage limit trajectories are chosen as the base speed is exceeded. The torque and flux trajectories show that the transition from MTPA to field weakening operation is smooth. The speed estimation is effective even in the field weakening region since the speed estimation error is kept small during the acceleration and reduces to zero at steady-state.

With optimized IPM2, at load condition, the flux-weakening control tracks voltage limited maximum output trajectory when the speed is greater than the critical speed. The mechanical speed response for an acceleration from 0 to $6230 \mathrm{r} / \mathrm{min}$ is shown in the Fig. 21. The transition to voltage limited trajectory was very smooth.

\section{CONCLUSIONS}

In this paper, a prototype segmented IPM machine for the starter/alternator of automobiles has been further optimized and designed. Cogging torque has been greatly reduced. A high torque output at start is obtained at very low speed and 


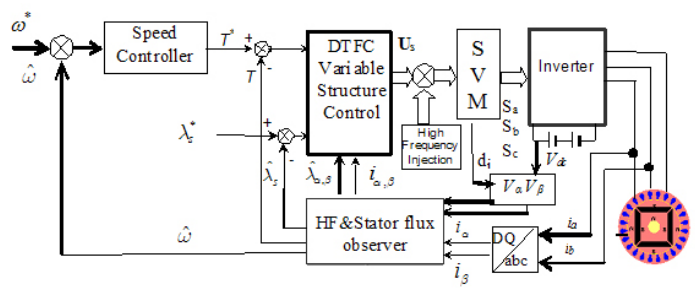

Fig. 15. A variable structure DTFC IPM drive with sensor-less operation technologies.
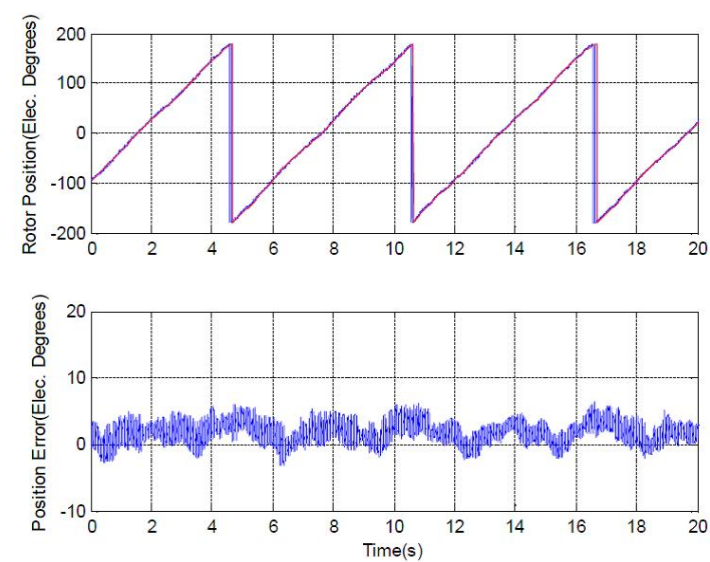

Fig. 16. Estimated and actual rotor positions and corresponding position estimation error of the sensor-less DTFC drive under full-load condition at 5rpm ((Experimental results).
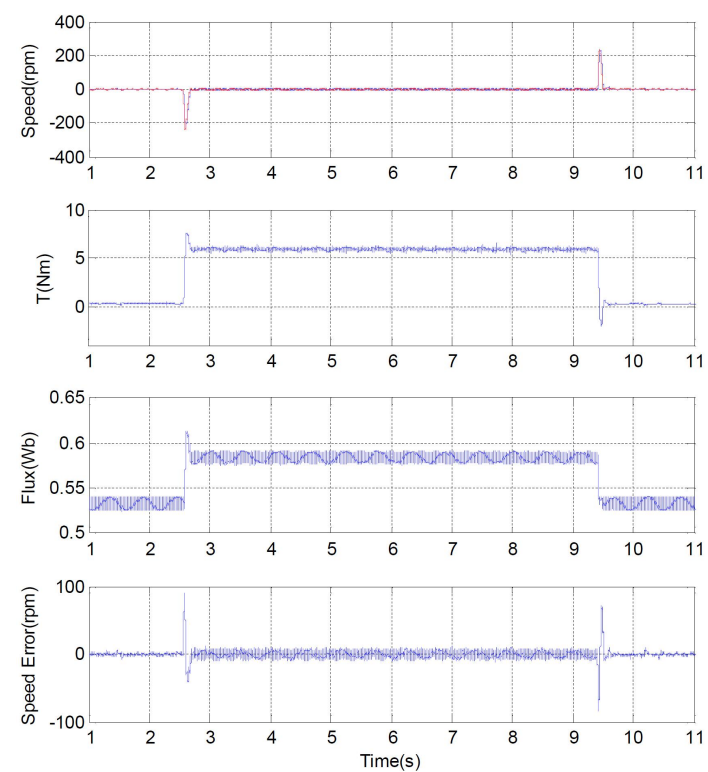

Fig. 17. Dynamic performance of the sensorless DTFC drive due to full-load steps at standstill ((Experimental results).
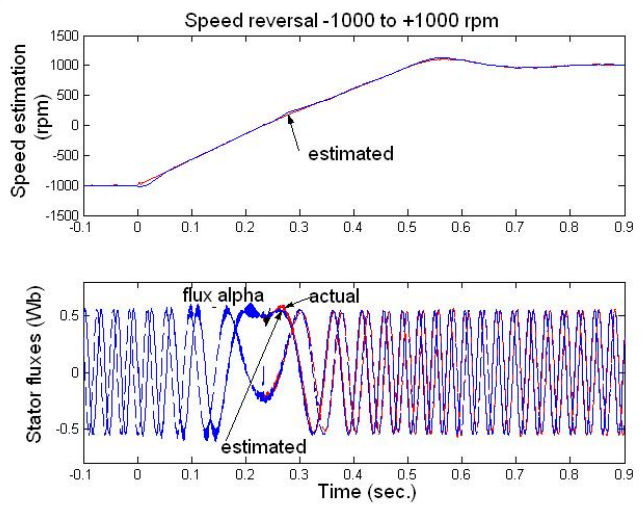

Fig. 18. Speed and flux estimation in the sensor-less operation, reversal from -1000 to $+1000 \mathrm{rpm}$ (Experimental results).
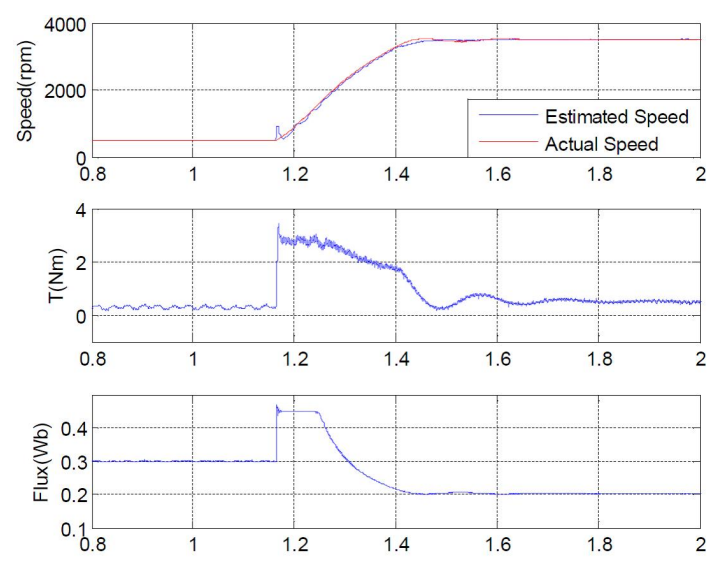

Fig. 19. Sensorless speed dynamics under maximum torque per Ampere(MTPA) and field weakening (Experimental results).

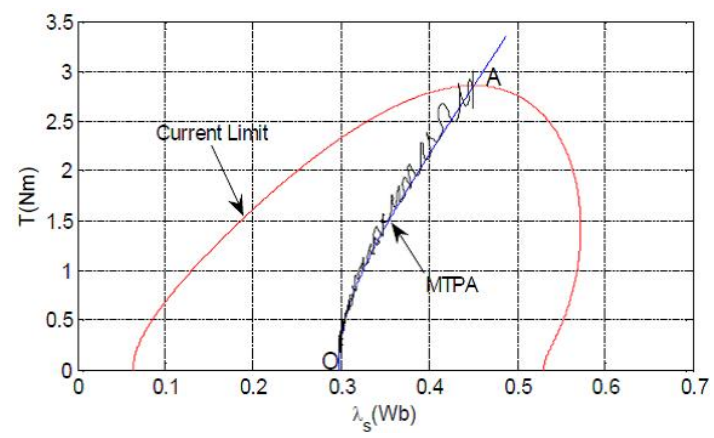

(a)

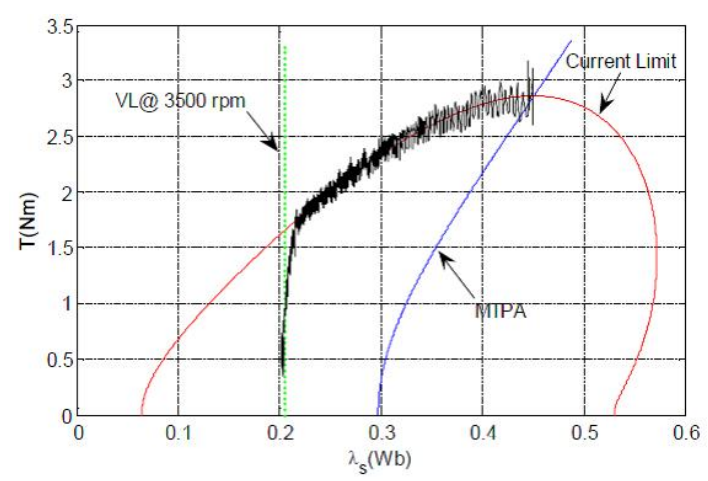

(b)

Fig. 20. Torque and flux trajectories of the DTFC drive on the $T-\lambda_{s}$ plane under field-weakening (Experiment results). 


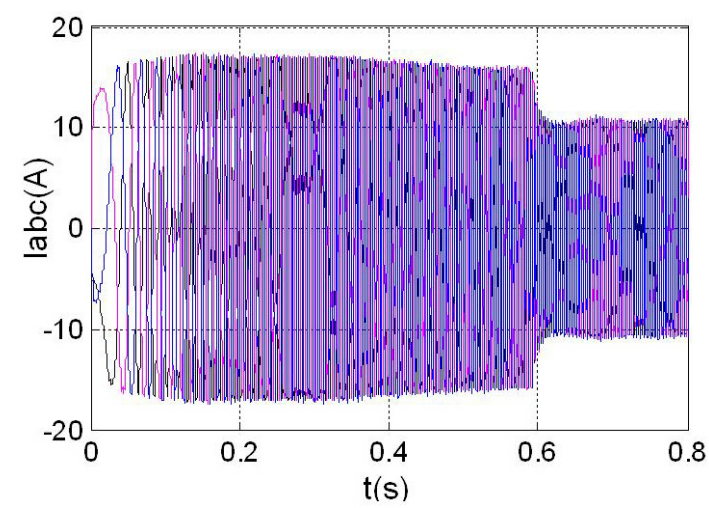

(a)

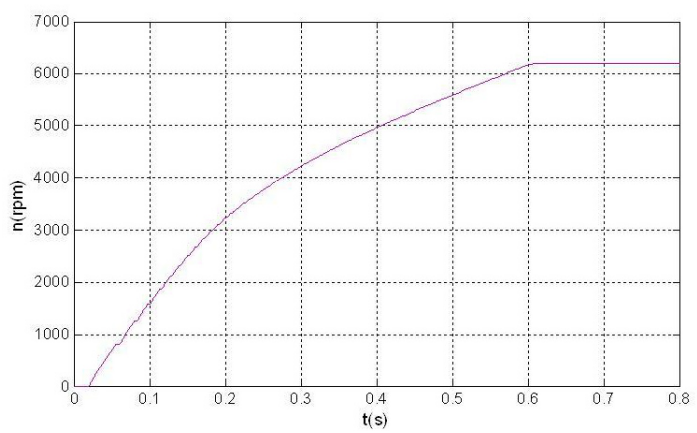

(b)

Fig. 21. Three-phase stator currents and actual mechanical speed of the IPM2 (experimental results).

the flux density of teeth and air gap is well distributed. A highfrequency carrier injection method and an improved stator flux observer based on the virtual rotor flux have been integrated with DTFC drive and used for test validation under sensor-less operation. The techniques work well at very low frequency regions where full torque is required. Apparently, the virtual flux based stator-flux observer can satisfy wide speed range ISA applications. Test results with full starting torque over a wide speed range have been presented.

\section{APPENDIX}

TABLE I

PARAMETERS OF THE IPM1 MACHINE

\begin{tabular}{|l|l|l|}
\hline Number of pole-pairs & $\mathrm{P}$ & 2 \\
\hline Stator resistance & $\mathrm{R}$ & $5.8 \Omega$ \\
\hline Magnet flux linkage & $\lambda_{f}$ & $0.533 \mathrm{~Wb}$ \\
\hline d-axis inductance & $L_{d}$ & $0.0448 \mathrm{H}$ \\
\hline q- axis inductance & $L_{q}$ & $0.1024 \mathrm{H}$ \\
\hline Rated Torque & $T_{b}$ & $6 \mathrm{Nm}$ \\
\hline
\end{tabular}

TABLE II

PARAMETERS OF THE IPM2 MACHINE (OPTIMIZED)

\begin{tabular}{|l|l|}
\hline Phase Voltage (rms) & $20.2 \mathrm{~V}$ \\
Phase Current(rms) & $12 \mathrm{~A}$ \\
Rated power & $550 \mathrm{~W}$ \\
d-axis inductance & $2.3493 \mathrm{mH}$ \\
q-axis inductance & $3.1773 \mathrm{mH}$ \\
Magnet flux linkage & $0.02377 \mathrm{~Wb}$ \\
Stator Resistance & $0.1765 \mathrm{ohm}$ \\
Rated speed & $1750 \mathrm{rpm}$ \\
Number of pole-pairs & 2 \\
\hline
\end{tabular}

\section{ACKNOWLEDGMENT}

This work was supported by National Natural Science Foundation of China (50777013).

\section{REFERENCES}

[1] J. G. Kassakian, J. M. Miller, and N. Traub, ”Automotive electronics power up," Spectrum, IEEE, Vol. 37, No. 5, pp. 34-39, May 2000.

[2] E. C. Lovelace, T. M. Jahns, J. L. Kritley Jr., and J. H. Lang, "An Interior PM Starter/Alternator for Automotive Applications," in Proc. International Conference on Electric machines(ICEM'98), Vol. 1, 1998.

[3] E. C. Lovelace, T. M. Jahns, J. Wai, T. Keim, J. H. Lang, D. D. Wentzloff, F. Leonardi, and J. M. Miller, "Design and experimental verification of a direct-drive interior PM synchronous machine using a saturable lumped parameter model," in Proc. Ind. Appl. Conf., 37th IAS Annual Meeting, Vol. 4, pp. 2486-2492, 2002.

[4] R. Dutta, M. F. Rahman, and M. A. Rahman, "An IPM machine with segmented magnet rotor for integrated starter alternator," In 3rd International Conference on Electrical and Computer engineering, 2004.

[5] R. Dutta and M. F. Rahman, "A segmented magnet interior permanent magnet machine with wide constant power range for application in hybrid vehicles," in Proc. 2005 IEEE Conf. Veh. Power Propulsion (VPP), pp. 288-293, 2005

[6] M. F. Rahman, Md. E. Haque, Lixin Tang, and Limin Zhong, "Problems associated with the direct torque control of an interior permanent-magnet synchronous motor drive and their remedies," IEEE Trans. Ind. Electron., Vol. 51, No. 4, pp. 799-809, Aug. 2004.

[7] M. E. Haque, L. Zhong, and M. F. Rahman, "A sensorless initial rotor position estimation scheme for a direct torque controlled interior permanent magnet synchronous motor drive," IEEE Tran. Power Electron., Vol. 18, pp. 1376-1383, Nov. 2003.

[8] L. A. Jones and J. H. Lang, "A state observer for the permanent-magnet synchronous motor," IEEE Trans. Ind. Electron., Vol. 36, pp. 374-382, Aug. 1989.

[9] J. F. Moynihan, M. G. Egan, and J. M. D. Murphy, "The application of state observers in current regulated PM synchronous drives," in Industrial Electronics, Control and Instrumentation, 1994. IECON '94., 20th International Conference on, Vol. 1, pp. 20-25, 1994.

[10] C. Lascu, I. Boldea, and F. Blaabjerg, "A modified direct torque control for induction motor sensorless drive," IEEE Trans. Ind. Electron., Vol. 36, pp. 122-130, Jan./Feb. 2000.

[11] M. Elbuluk and C. Li, "Sliding mode observer for wide-speed sensorless control of PMSM drives," Industry Applications Conference, 2003. 38th IAS Annual Meeting. Conference Record, Vol.1, pp. 480-485, 2003.

[12] Z. Chen, M. Tomita, S. Doki, and S. Okuma, "An extended electromotive force model for sensorless control of interior permanent-magnet synchronous motors," IEEE Trans. Ind. Electron., Vol. 50, pp. 288-295, Apr. 2003

[13] S. Bolognani, R. Oboe, and M. Zigliotto, "Sensorless full-digital PMSM drive with EKF estimation of speed and rotor position," IEEE Trans. Ind. Electron., Vol. 46, pp. 184-191, Feb. 1999.

[14] L. Harnefors, "Speed estimation from noisy resolver signals," Sixth International Conference on Power Electronics and Variable Speed Drives, No. 429, pp. 279-282, 1996.

[15] Z. Xu and M. F. Rahman, "Direct torque and flux regulation of an IPM synchronous motor drive using variable control approach," IEEE Trans.Power Electron., Vol. 22, pp. 2487-2498, Nov. 2007.

[16] L. Zhong, M. F. Rahman, W. Y. Hu, and K. W. Lim, "A direct torque controlled interior permanent magnet synchronous motor drive incorporating field weakening," IEEE Trans. Ind. Applicat., Vol. 34, pp. 1246-1253, Nov./Dec. 1998.

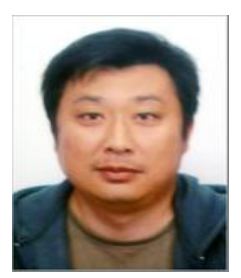

Zhuang Xu (S'01) received the M.Eng.Sci. and Ph.D degrees in electrical engineering from the University of New South Wales, Sydney, Australia, in 1999 and 2006, respectively. He worked with the Energy System Group, University of New South Wales, from 2001 to 2005. He became an Associate Professor with the Harbin Institute of Technology, Harbin, China, in 2006, where his research was focused on power electronics and high-performance electrical drives. Dr. Xu received three Best Paper Awards at IECON'04 from the IEEE Industrial Electronics Society, IEEE ICEMS 2010 and IEEE ECCE Asia-ICPE 2011,respectively. 


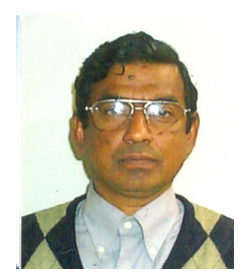

M. F. Rahman (M'79-SM'96) received the B.Sc.Eng. degree in electrical engineering from the Bangladesh University of Engineering and Technology, Dhaka, and the M.S. and Ph.D. degrees from the University of Manchester Institute of Science and Technology, Manchester, U.K. in 1975 and 1978, respectively. He subsequently worked as a System Design Engineer at the General Electric Company, U.K., for two years before joining the National University of Singapore in 1980. He joined the University of New South Wales, Australia, in 1988 as a Senior Lecturer where he is currently a full Professor. His research interests are in power electronics, motor drives, electrical machines and motion control systems, and electromagnetics.

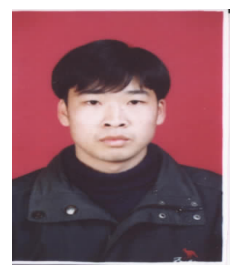

G. Wang was born in Fujian, China, in 1978. He received the $\mathrm{Ph} . \mathrm{D}$ in electrical engineering from Harbin Institute of Technology, China, in 2009. He is currently a Lecturer at the same university. His research interests include power electronics and motor drives.

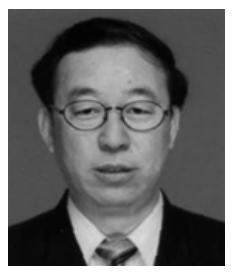

Dianguo Xu (M'97) received the B.S. degree in control engineering from Harbin Shipbuilding Engineering Institute, China, in 1981, and the M.S. and Ph.D. degrees in electrical engineering from Harbin Institute of Technology in 1984 and 1990, respectively. Since 1994, he has been a Professor with the Department of Electrical Engineering, Harbin Institute of Technology. His current research interests include ac motor drives, utility applications of power electronics, motion control, appliance intelligent control, lighting electronics and robot control system Prof. Xu was the Department Head from 1992 to 1998, Dean of School of Electrical Engineering and Automation from 1998 to 2010, and Assistant President of Harbin Institute of Technology from 2010 to now. Professor Xu is the chairman of IEEE Harbin section, a member of China Electrotechnical Society (CES), a member of China Automation Association (CAA), and a member of China Power Supply Society (CPSS). Prof. Xu has been a member of International Steering Committee, PEDS; a member of Technical Program Committee, ICEMS; a member of Technical Program Committee, IPEMC; Prof. $\mathrm{Xu}$ is the technical program chair of VPPC2008 and IPEMC2012. 